\title{
REGIONAL OPTIONS OF THE RUSSIAN LANGUAGE IN THE EDUCATIONAL SYSTEM (ON THE MATERIAL OF THE CHEBOKSARY REGIONAL DIALECT)
}

\author{
Tamara N. Erina ${ }^{1}$, Eduard V. Fomin ${ }^{2 \star}$, Alena M. Ivanova ${ }^{3}$, Nikolay A. Petrov ${ }^{4}$, \\ Aleksey A. Pushkin \\ ${ }^{1}$ Assoc. Prof., I. N. Ulyanov Chuvash State University, RUSSIA, tnerina@rambler.ru \\ ${ }^{2}$ Assoc. Prof., Chuvash State Institute of Culture and Arts, RUSSIA, yeresen@yandex.ru \\ ${ }^{3}$ Prof., Dr., I. N. Ulyanov Chuvash State University, RUSSIA, amivano@rambler.ru \\ ${ }^{4}$ Assoc. Prof., I. N. Ulyanov Chuvash State University, RUSSIA, homo-sapiens10@rambler.ru \\ ${ }^{5}$ Assoc. Prof., I. N. Ulyanov Chuvash State University, RUSSIA, fldh@mail.ru \\ ${ }^{*}$ Corresponding Author
}

\begin{abstract}
World languages are a collection of a large number of variations. A good example is English, represented by British, American, Australian, New Zealand, and other national variations. The Russian language is more monolithic in this regard, although the processes of its regionalization are at full swing, too. As a rule, the regiolects of the Russian language are manifested in oral speech, but at the same time they begin to find expression in written texts as well. The purpose of the research is to study regional elements called "cheboksarizms" in the linguistic literature. The linguistic facts making up the material for the research were obtained through direct observations and following recordings of oral speeches of students by the authors of the paper in the conditions of the city of Cheboksary, the capital of the Chuvash Republic, Russia. The research work is based on a qualitative analysis of factual material in speech culture perspective. The authors consider the material from the standpoint of its intrusion into written texts. The research is that of generalizing character. Cheboksary is the capital of the Chuvash Republic, Russia. The population of Cheboksary is 500 thousand people; with the agglomeration included its population is more than 700 thousand people. Officially there are two state languages in the republic - Chuvash and Russian. Their active interaction in the second half of the twentieth century resulted in the emergence of a stable local version of the Russian language. The main peculiarities of the Cheboksary regiolect lie in that it is a kind of literary language being formed with the help of a limited number of linguistic elements due to their multiple reoccurrence. In conditions of national regions having a good command of the Russian language at a high quality level becomes a priority in Russia. In the oral speech of students there is a great deal of lexical and grammatical "chuvashisms". They tend to make their way into written texts, too. The penetration of "cheboksarisms" of oral speech type into written texts contributes to consolidating written traditions and codifying regional features of the Russian language.
\end{abstract}

Keywords: regional dialect, literary language, substrate, linguistic education. 


\section{INTRODUCTION}

The Russian language is a monolithic formation, however, it has been undergoing through a new regionalization processes wave recently (Bokhieva, Stepanova, 2012; Bystrova, 2001; Krysin, 2004; Livinskaya, 2015; Oglezneva, 2008; Prokurovskaya, 1996; Trubinsky, 1991).

As a rule, the regiolects of the Russian language are believed to be a linguistic phenomenon referring to oral speech, but at the same time they have been noted to expose themselves in written texts as well. This is due to the fact that regionalisms are often not recognized as such by native speakers.

It seems that in teaching the Russian language, especially in a national language environment as the Chuvash one, it is necessary for the learners of Russian to strive to master its literary norm taking into account all regional peculiarities.

\section{METHODOLOGY}

The purpose of the research is to study regional elements in the speech of students called "cheboksarizms" in the linguistic literature. The material for the research was compiled of the linguistic facts obtained by the authors of the paper through direct observations and recordings of oral speeches of students in the conditions of the city of Cheboksary, the capital of the Chuvash Republic, Russia. The work is based on a qualitative analysis of factual material in speech culture perspective. The authors consider the material from the standpoint of its penetration into written texts. The research being of a generalizing character it sums up the project work done by now.

New qualitative parameters of Russian speech are formed in the conditions of the Chuvash-Russian interethnic interaction in the capital of the Chuvash Republic. They are on the way of becoming a model for all residents of the republic, thus distinguishing them among the representatives of other regions.

\section{OPINIONS AND DISCUSSION}

\subsection{Cheboksary Regiolect: General Information}

Cheboksary is the capital of the Chuvash Republic, Russia. The population is half a million people, with all agglomeration included it is more than 700 thousand people. There are two official languages in the republic - Turkic Chuvash and Slavic Russian. Their active interaction in the second half of the twentieth century resulted in the emergence of a stable local version of the Russian language (Erina, Fomin, 2018). One of the factors forming a highly valued attitude towards the Russian language in Chuvashia is its prestige: "Working at school in the town of Novocheboksarsk, I had no problems with teaching Russian. Everyone studied it with great interest. After moving to the region with the Russian population I witnessed the students' indifference to the subject" (O., 45 years old). The speech of residents of Cheboksary is not burdened with Russian dialects. Russian is initially mastered in its literary form, that's why the opinion of a resident of the Moscow region who visited Cheboksary in early 2000 seems to be quite fair: "The Russian language in Chuvashia is very beautiful and correct". The main feature of the Cheboksary regiolect is that it is literary in its essence. It functions on the basis of a limited number of linguistic elements due to their multiple reoccurrence in oral speech (Erina, Fomin, 2020). The Cheboksary regiolect has valuable properties: "I went to the South. A few days later I realized that I was missing the usual Cheboksary environment with Chuvash inclusions, so I began to create it around me" (S., 30 years old); "Now I live in Moscow. Whenever we meet with fellow countrymen we begin to speak in Cheboksary style. Nostalgia..." (An anonymous respondent's confession).

\subsection{Specific Features of the Cheboksary Regiolect of the Russian Language in the Educational System}

The Cheboksary regiolect has its features at all levels of the language system (Erina, Fomin 2021). We agree that the number of "cheboksarism" markers is not abundant, and there cannot be infinitely many of them, otherwise a question of another language might have arisen.

\subsubsection{Phonetic Peculiarities of the Cheboksary Regiolect}

The main phonetic feature of the speech of the Cheboksary people is the literal pronunciation, with the exception of the cases referring to the phonetic phenomenon called "okanye" meaning the retention of unstressed 'o' in Russian dialects. Anyhow Cheboksary people have so far manage to cope with it as a sign that creates the Chuvash accent. The rest of the rules of Russian pronunciation including reduction of vowels in unstressed positions, merged pronunciation of prefixes with significant words are more subtle and complex, and they are still hard for learners of Russian to overcome these difficulties. Meanwhile, the literal 
pronunciation has a positive side in educational practice: it allows the learners to write correctly in Russian.

\subsubsection{Lexical Peculiarities of the Cheboksary Regiolect}

The lexical originality of the Cheboksary regiolect is expressed, as a rule, in the use of regionally determined urbanonyms in speech, as well as of exoticisms of Chuvash origin including:

the names of the streets as Khuzangai Street and Elger Street named as such in commemoration of outstanding Chuvash poets P. Khuzangai and S. Elger, Anatkas meaning 'down street';

the names of the rivers as Cheboksarka, Sugutka;

the names of the villages as Algeshevo, Lapsary;

the names of the parks and forests as Berendeevsky, Lakreevsky;

the names of national foods and drinks as shyrtan meaning 'homemade sausage', turăh meaning 'sour milk'; the names of holidays as Akatui meaning 'spring holiday'.

This lexical layer cannot but attract one's attention. Anyhow the participation of the lexical layer used in the formation of the Cheboksary regiolect adds some regionally determined coloring to the Russian language.

Above mentiond lexical markers, i.e. urbanonyms and exoticisms including frequently used names of Chuvash foods and drinks, dishes, holidays gain an official status, and got codified in documents. They are included in the dictionary of Cheboksary residents.

\subsubsection{Grammatical Peculiarities of the Cheboksary Regiolect}

The grammatical peculiarities of the Cheboksary regiolect of the Russian language are formed by a number of expressive markers:

1) Conveying the meaning of possessivity by means of an analytical form, e. g. u menya dom instead of moi dom 'My house';

2) Making utterances interrogative using the particle chto li, e. g. Pridyosh' chto li? instead of Pridyosh? 'Will you come?';

3) Making the requests more polite by using the colloquial particle -ka, e. g. skazhite-ka instead of skazhite, pozhaluista 'Tell, please'.

Grammatically determined cheboksarisms are rarely codified in written texts. It should be noted that this kind of 'codification' on the whole is of the spontaneous character, since it usually occurs in the written works of students, and it rarely goes beyond the educational system. Of the markers mentioned above only the analytical form expressing possessivity claims for being codified. Anyhow students have a clear cut understanding of spoken and written forms of expressing the idea of possessivity.

\subsubsection{Stylistic Peculiarities of the Cheboksary Regiolect}

In linguistics, it is not customary to talk about stylistic interference because the essentials of stylistics are considered at the level of linguistic units already. One might think there is no necessity for a holistic stylistic analysis. Nevertheless, the mutual influence of the contacting peoples and cultures can be observed in stylistic domain of interacting languages as well. The most interesting example of stylistic interference in the Chuvash-Russian relations is the usage of the speech unit aydate-ka. Ayda in the speech of Cheboksary residents is a stylistically neutral interjection calling for an action. Meanwhile in Russian literary speech the units ayda and -ka are recognized as vernaculars. The reasons for such speech behavior of Cheboksary residents might be accounted for by the Chuvash language tradition, in which ayda is a word with a neutral connotation, and the particle -ka is the marker of high style used to express an informal request.

\subsubsection{Speech Peculiarities of the Cheboksary Regiolect}

The speech of the Cheboksary people is distinguished by its verbosity. According V. N. Pushkin, a wellknown scholar in the field of Chuvash Studies, the phenomenon of verbosity might be accounted for by insufficient depth of knowledge of the speaker on the subject-matter of the talk in general.

Outwardly the speaker leaves the impression of a man having an excellent command of the language: he does not have an accent, he speaks fluently, but his thoughts are superficial.

For comparison the scholar cites an example of the Balts who spoke Russian with an accent and found it 
difficult to find words, but at the same time expressed quality ideas. The loudness of the speech of Cheboksary residents, according to observations, is higher than that of the Chuvash living outside Cheboksary. According to N. I. Gerasimova, a scholar in the area of Chuvash Culture Studies, the loudness of the speech of Cheboksary residents is due to their desire to show the society a good level of command of the Russian language.

\subsubsection{Spelling and Punctuation Specifics of the Cheboksary Region}

Spelling and punctuation types of deviations from the literary norm are not determined by regional peculiarities. In mastering the spelling rules the same difficulties arise that are inherent to all learners of the Russian language. At the very outset of inventing the alphabet, the Chuvash spelling was greatly influenced by the Russian one. At least for this reason the possible manifestation of the substrate Chuvash specificity in the field of spelling and punctuation is practically not noted. The consolidation of speech-type "cheboksarisms" in the written tradition strengthens and codifies the regional features of the Russian language. The deliberate reproduction of the features of the Cheboksary regiolect in future may lead to its realization as a new supra-ethnic civil-identification of the inhabitants of Cheboksary and Chuvashia. In this aspect, it seems possible to codify "cheboksarisms" in scientific literature and introduce topics related to the regional peculiarities of the Russian language into the educational system.

\section{CONCLUSION}

The formation of the Cheboksary regiolect of the Russian language has been taking place continuously since the late XX century. At present its peculiarities are coming out to the fore as never before, since in the Chuvash ethnic environment the processes of a linguistic shift in favor of Russian have accelerated. At the same time there is not a very high-quality assimilation of Russian speech culture yet. On the whole, it may seem that the speech of the inhabitants of Cheboksary is sustained in the spirit of the literary language and meets the requirements of the literary norms. However, the influence of the Chuvash substrate is strong enough in it. It is primarily manifested in the use of Russian units according to the rules and speech patterns of the Chuvash language.

The educational system in Chuvashia is focused on mastering the Russian language at a high quality level. At the same time, the practice of teaching the Russian language in national schools has been focused on the assimilation of theoretical information about the language for quite a long time. The teaching experience based on communication with students as schools and universities, and their written works shows that the language teaching strategy needs refocusing by turning the attention towards teaching speaking. The priority area of functioning of the Cheboksary regiolect is oral speech. In some cases, speech elements get codified within the written sphere, thereby confirming the position of the regional variant of the Russian language. According to our observations the society having achieved perfect knowledge of the Russian language subsequently may reproduce the Cheboksary regiolect. In this regard, it can become a new basis for the supranational civil self-identification of the inhabitants of the Chuvash Republic.

\section{ACKNOWLEDGMENTS}

The study was financially supported by the Russian Foundation for Basic Research and the Chuvash Republic as part of Scientific Project No. 19-412-210001 p_a.

\section{REFERENCE LIST}

Bohieva, M. V., \& Stepanova, I. Zh. (2012). Regional Variation of the Russian Language in Transbaikalia: Issues of Stratification. NSU Bulletin. Series: History, Pholilogy, vol. 11.

Bystrova, E. A. (2001). Problems and Prospects of Teaching Russian at School. Russian Language at School: Experience, Problems, Prospects.

Erina, T. N., \& Fomin, E. V. (2020). Russian Language in Modern Conditions: Cheboksary Regiolect. European Proceedings of Social and Behavioural Sciences, vol. 92.

Erina, T. N., \& Fomin, E. V. (2018). Extralinguistic Factors of Functioning of the Cheboksary Regiolect. Russian Language in Terms of Bi- and Polylingualism.

Erina, N. N., \& Fomin, E. V. (2021). This is Cheboksary Speaking. 
Proceedings of INTCESS 2022-9th International Conference on Education \& Education of Social Sciences 17-18 January 2022- Online Conference

Krysin, L. P. (2004). On the Variation of the Russian Language in Foreign National Conditions. The Russian Word of One's Own and Someone Else's: Research on Modern Russian Language and Sociolinguistics.

Livinskaya, I. V. (2015). On the Issue of Regional Variation of the National Language. MGOU Bulletin. Series: Russian Philology, vol. 6.

Oglezneva, E. A. (2008). Far Eastern Region of the Russian Language: Features of Formation. Russian Language in Scientific Coverage, vol. 2.

Prokurovskaya, N. A. (1996). The City in the Mirror of its Language: on the Material of Izhevsk.

Trubinskij, V. I. (1991). Modern Russian Regiolects: Sings of Formation. Pskov Dialects and their Environment. 